\title{
Perilaku Higiene Sanitasi Penjamah Makanan di Rumah Makan Padang Wilayah Kerja Puskesmas Basuki Rahmat Kota Palembang
}

\author{
Hygiene Sanitation Behavior Of Food Manufacturer In The Padang \\ Restaurant In The Working Area Of The Puskesmas Of Palembang City
}

\author{
Khairil Anwar ${ }^{1 *}$, Diah Navianti ${ }^{1}$, Sasma Rusilah ${ }^{1}$
}

\author{
${ }^{1}$ Jurusan Kesehatan Lingkungan Politeknik Kesehatan Kementerian Kesehatan \\ Palembang, Sumatera Selatan, Indonesia \\ *Korespondensi penulis: khairilanwar46@ymai.com
}

Penyerahan: 28-09-2020, Perbaikan: 27-12-2020, Diterima: 05-01-2021

\begin{abstract}
Food Hygiene sanitation is personal hygiene, especially food handlers who work directly in food processing because food handling can contaminate food. Therefore, individual hygiene in food processing is one of the important aspect so that food products are safe for consumption. In addition to processing, proper and correct storage and presentation of food are also important in order to maintain the quality and safety of processed food products. The aim of this study was to ascertain the behavior of food handlers hygiene sanitation in a few Padang Restaurants in the working area of the Basuki Rahmat Community Health Center, Palembang City. This research method was a descriptive survey, which was to see the description of the behavior of food handlers hygiene sanitation in while. The results of this study showed that 28 respondents (68.3\%) were highly educated, 37 respondents (90.2\%) had good knowledge, 28 respondents $(68.3 \%)$ had good actions, 39 respondents (95.1\%) had good attitude, highly educated food handlers have good actions 25 handlers (61.0\%), while food handlers who have good knowledge and good actions 27 food handler (65.8\%). It is recommended that the person in charge of the restaurant to further improve the knowledge, attitudes and actions of food handlers and for the Palembang City Health Office to conduct regular inspection of restaurants and hold sanitation hygiene training for food handlers.
\end{abstract}

Keywords: hygiene sanitation behavior, food handler, Padang restaurant, Palembang

\begin{abstract}
ABSTRAK
Higiene sanitasi makanan adalah kebersihan individu terutama penjamah makanan yang bekerja langsung dalam pengolahan pangan karena penjamah makanan dapat mencemari bahan pangan. Oleh karena itu kebersihan individu dalam pengolahan makanan merupakan salah satu hal yang penting agar produk pangannya aman untuk dikonsumsi. Selain pengolahan, penyimpanan dan penyajian makanan yang baik dan benar juga merupakan hal yang penting agar dapat menjaga mutu dan keamanan hasil olahan pangan. Tujuan penelitian ini adalah diketahuinya prilaku Higiene Sanitasi Penjamah Makanan di Rumah Makan Padang Wilayah Kerja Puskesmas Basuki Rahmat Kota Palembang. Metode penelitian ini adalah survey bersifat deskriftif yaitu melihat gambaran prilaku hygiene sanitasi penjamah makanan di Rumah makan Padang Wilayah Kerja Puskesmas Basuki Rahmat Kota Palembang. Hasil Penelitian ini menunjukkan bahwa 28 responden $(68,3 \%)$ berpendidikan tinggi, 37 responden $(90,2 \%)$ yang berpengetahuan baik, 28 responden $(68,3 \%)$ yang memiliki tindakan baik, 39 responden $(95,1 \%)$ yang memiliki sikap baik, penjamah makanan yang berpendidikan tinggi memiliki tindakan baik sebanyak 25 penjamah $(61,0 \%)$, sedangkan penjamah makanan yang memiliki pengetahuan baik dan tindakan baik sebanyak 27 penjamah makanan
\end{abstract}

Jurnal Dunia Kesmas, Vol. 9 No. 4, Oktober 2020, hal. 512 - 520

512

ISSN 2301-6604 (Print), ISSN 2549-3485 (Online)

http://ejurnalmalahayati.ac.id/index.php/duniakesmas/index 
(65,8\%). Disarankan kepada penanggung jawab rumah makan agar dapat lebih meningkatkan pengetahuan, sikap dan tindakan penjamah makanan $\mathrm{dan}$ kepada Dinas Kesehatan Kota Palembang agar dapat melakukan inspeksi secara berkala terhadap rumah makan dan mengadakan pelatihan higiene sanitasi bagi penjamah makanan.

Kata Kunci : Perilaku higiene sanitasi, penjamah makanan, rumah makan Padang, Palembang

\section{PENDAHULUAN}

Berdasarkan UU Republik Indonesia No.18 Tahun 2012 Tentang Pangan, agar pangan dapat dikonsumsi dengan aman maka perlu dilakukan higiene sanitasi. Dalam menangani bahaya pada pangan, setiap orang yang terlibat dalam rantai pangan wajib mengendalikan risiko bahayanya, baik yang berasal dari peralatan yang digunakan, bahan baku makanan, sarana, proses produksi, maupun perorangan sehingga keamanan terjamin (Kemenkes, 2017).

Sebagian besar pengusaha rumah makan di Indonesia belum paham dalam persyaratan higiene sanitasi yang erat hubungannya dengan kesehatan. Pada dasarnya pengusaha rumah makan dalam menjalankan usahanya hanya memikirkan segi komersial saja dan kurang memperhatikan peraturan tentang kesehatan dan sanitasi tempat umum. Permasalahan yang ada dalam pengawasan higiene sanitasi yakni perlu adanya peraturan/kebijakan yang mengatur mengenai pendirian dan pengelolaan sanitasi tempat-tempat umum yaitu termasuk rumah makan (Setiyobroto, 2017).

Hasil penelitian pelaksanaan higiene dan sanitasi makanan ditinjau dari aspek penjamah makanan (Foodhandler) Di RC (Retreat Center) Sukamakmur ditemukan bahwa $37,5 \%$ penjamah makanan belum mengetahui wajib memeriksakan kesehatannya setiap 6 bulan sekali. Sebanyak $50 \%$ petugas penjamah makanan tidak menggunakan penutup kepala sewaktu bekerja, 100 $\%$ petugas penjamah makanan bekerja hanya kadang-kadang menggunakan pakaian kerja dan hanya kadang-kadang petugas penjamah makanan pada saat keluar dari WC/toilet mencuci tangan menggunakan sabun terlebih dahulu (Meliala, 2017).

Penjamah makanan merupakan orang yang secara langsung berhubungan dengan makanan dan peralatan mulai dari tahap persiapan, pembersihan, pengolahan, pengangkutan, sampai dengan penyajian. Berdasarkan Kepmenkes No 1098 tahun 2003, tenaga/karyawan pengolah makanan harus memiliki sertifikat higiene sanitasi makanan, berbadan sehat yang dibuktikan dengan surat keterangan dokter, tidak mengidap penyakit menular seperti typhus, tuberkulosis dan lain-lain atau pembawa kuman (carrier) serta setiap karyawan harus memiliki buku pemeriksaan kesehatan yang berlaku. Penjamah makanan harus melakukan pemeriksaan kesehatan 2 (dua) kali dalam setahun.

Berdasarkan data profil Puskesmas Basuki Rahmat bahwa diwilayah Puskesmas Basuki Rahmat terdapat 10 rumah makan Padang dan 41 Penjamah Makanan dan hasil survey pendahuluan yang dilakukan oleh peneliti terhadap penjamah makanan di rumah makan Padang terlihat sebagian besar penjamah makanan belum memakai Alat 
Pelindung Diri (celemek, penutup kepala, masker dan sarung tangan) dan sebagian besar pada rumah makan padang di wilayah Puskesmas Basuki Rahmat belum memiliki Surat Keterangan Laik Sehat. Adapun tujuan penelitian ini adalah untuk mengetahui perilaku penjamah makanan rumah makan Padang di wilayah kerja Puskesmas Basuki Rahmat tahun 2020.

\section{METODE}

Penelitian ini merupakan penelitian deskriptif dengan pendekatan cross sectional dimana variabel dependen dan independen diukur sekaligus pada waktu yang bersamaan. Penelitian ini dilaksanakan di rumah makan Padang Wilayah Kerja Puskesmas Basuki Rahmat Kota Palembang. Populasi dalam penelitian adalah semua penjamah makanan yang ada di rumah makan Padang yang tidak memiliki sertifikat Laik Higiene, dari 10 rumah makan Padang dengan jumlah penjamah makanan sebanyak 41 orang (Profil Puskesmas Basuki Rahmat). Sampel adalah semua penjamah makanan di rumah makan Padang yang sesuai dengan kriteria yang didapatkan dengan metode Pusposive sampling. Semua responden diberikan informed consent sebagai bukti persetujuan ikut dalam penelitian. Dalam penelitian ini kuesioner yang ditanyakan kepada responden berisi tentang pendidikan responden yang terdiri dari 2 variabel yaitu tinggi (responden yang berpendidikan minimal SMA) dan variabel rendah (responden yang berpendidikan dibawah SMA). Selanjutnya kuesioner yang ditanyakan kepada responden berisi tentang pengetahuan terdiri dari 2 variabel yaitu baik (responden yang menjawab pertanyaan dengan benar $\geq 70 \%$ dan variabel buruk (responden yang menjawab pertanyaan dengan benar $<70 \%$ ), sikap terdiri dari 2 variabel yaitu baik (responden yang menjawab pertanyaan dengan benar $\geq 70 \%$ ) dan variabel buruk (responden yang menjawab pertanyaan dengan benar $<70 \%$ ) dan tindakan responden yang terdiri dari 2 variabel yaitu baik (responden yang menjawab pertanyaan dengan benar $\geq 70 \%$ ) dan variabel buruk (responden yang menjawab pertanyaan dengan benar $<70 \%$ ).

Data di analisis univariat dengan deskriptif digunakan untuk menggambarkan prilaku Higiene Sanitasi Penjamah Makanan di rumah makan Padang Wilayah Kerja Puskesmas Basuki Rahmat Kota Palembang.

\section{HASIL}

Berdasarkan hasil penelitian yang telah diperoleh dengan mengadakan wawancara dan observasi terhadap penjamah makanan di rumah makan Padang Wilayah Kerja Puskesmas Basuki Rahmat Kota Palembang, maka didapatkan hasil sebagai berikut:

$\begin{array}{llr}\text { Tabel 1. } & \begin{array}{c}\text { Distribusi } \\ \text { Makanan }\end{array} & \begin{array}{r}\text { Frekuensi } \\ \text { Benjamah }\end{array} \\ \text { Tingkat } & \begin{array}{l}\text { Masarkan } \\ \text { Pendidikan, }\end{array} \\ \text { Pengetahuanganat } & \text { Sikap dan Tindakan }\end{array}$

\begin{tabular}{|c|c|c|}
\hline Kategori & Jumlah & $\begin{array}{c}\text { Persentase } \\
(\%)\end{array}$ \\
\hline \multicolumn{3}{|c|}{ Pendidikan } \\
\hline Tinggi & 28 & 68,3 \\
\hline Rendah & 13 & 31,7 \\
\hline \multicolumn{3}{|c|}{ Pengetahuan } \\
\hline Baik & 37 & 90,2 \\
\hline Buruk & 4 & 9,8 \\
\hline \multicolumn{3}{|l|}{ Sikap } \\
\hline Baik & 39 & 95,1 \\
\hline Buruk & 2 & 4,9 \\
\hline \multicolumn{3}{|l|}{ Tindakan } \\
\hline Baik & 28 & 68,3 \\
\hline Buruk & 13 & 31,7 \\
\hline Jumlah & 41 & 100 \\
\hline
\end{tabular}


Berdasarkan tabel 1 diatas dapat dilihat bahwa terdapat 28 responden $(63,3 \%)$ yang berpendidikan tinggi yaitu responden dengan pendidikan SMA dan Perguruan Tinggi dan terdapat 13 responden $(31,7 \%)$ yang berpendidikan rendah yaitu responden yang berpendidikan paling tinggi Sekolah Menengah Pertama. Responden yang berpengetahuan baik sebanyak 37 responden $(90,2 \%)$ yaitu responden yang mendapatkan skor $\geq 70$ dan 4 responden $(9,8 \%)$ yang memiliki pengetahuan buruk yaitu responden yang mendapatkan skor $<70$ dan terdapat 28 responden (68,3\%) memiliki tindakan baik yaitu responden yang mendapatkan skor $\geq 70$ dan 13 responden $(31,7 \%)$ yang memiliki tindakan buruk yaitu responden yang mendapatkan skor $<70$, serta terdapat 39 responden $(95,1 \%)$ yang memiliki sikap baik yaitu responden yang mendapatkan skor $\geq 70$ dan 3 responden $(4,9 \%)$ yang memiliki sikap buruk yaitu responden yang mendapatkan skor $<70$.

Tabel 2. Distribusi Frekuensi Tindakan Penjamah Makanan Berdasarkan Tingkat Pendidikan

\begin{tabular}{|c|c|c|c|c|}
\hline & & & Jumlah & Persentase \\
\hline Pendidikan & Baik & Buruk & & (\%) \\
\hline
\end{tabular}

\begin{tabular}{lcccccc} 
& Frekuensi & $\begin{array}{c}\text { Persentase } \\
(\%)\end{array}$ & Frekuensi & $\begin{array}{c}\text { Persentase } \\
(\%)\end{array}$ & Frekuensi & $\begin{array}{c}\text { Persentase } \\
(\%)\end{array}$ \\
\hline Rendah & 3 & 7,3 & 10 & 24,4 & 13 & 31,7 \\
Tinggi & 25 & 61,0 & 3 & 7,3 & 28 & 68,3 \\
Jumlah & 28 & 68,3 & 13 & 31,7 & 41 & 100
\end{tabular}

Berdasarkan tabel 2 diatas dapat dilihat bahwa responden yang berpendidikan rendah memiliki tindakan baik sebanyak 3 penjamah $(7,3 \%)$ dan penjamah makanan yang berpendidikan tinggi memiliki tindakan baik sebanyak 25 penjamah $(61,0 \%)$, sedangkan

penjamah makanan yang
berpendidikan rendah memiliki tindakan buruk sebanyak 10 penjamah $(24,4 \%)$ dan penjamah makanan yang berpendidikan tinggi memiliki tindakan buruk sebanyak 3 penjamah $(7,3 \%)$.

Tabel 3. Distribusi Frekuensi Tindakan Penjamah Makanan Berdasarkan Pengetahuan

\begin{tabular}{|c|c|c|c|c|c|c|}
\hline \multirow{3}{*}{ Pengetahuan } & \multicolumn{4}{|c|}{ Tindakan } & \multirow{3}{*}{$\begin{array}{l}\text { Jumlah } \\
\text { Frekuensi }\end{array}$} & \multirow{3}{*}{$\begin{array}{c}\text { Persentase } \\
\text { (\%) } \\
\text { Persentase } \\
(\%)\end{array}$} \\
\hline & \multicolumn{2}{|c|}{ Baik } & \multicolumn{2}{|c|}{ Buruk } & & \\
\hline & Frekuensi & $\begin{array}{c}\text { Persentase } \\
(\%)\end{array}$ & Frekuensi & $\begin{array}{c}\text { Persentase } \\
(\%)\end{array}$ & & \\
\hline Baik & 27 & 65,8 & 8 & 19,5 & 35 & 85,3 \\
\hline Buruk & 2 & 4,9 & 4 & 9,8 & 6 & 14,7 \\
\hline Jumlah & 29 & 70,7 & 12 & 29,3 & 41 & 100 \\
\hline
\end{tabular}

Berdasarkan tabel 3 diatas dapat dilihat bahwa responden yang memiliki pengetahuan baik dan memiliki tindakan baik sebanyak 27 penjamah makanan $(65,8 \%)$ dan yang memiliki pengetahuan baik 
dan memiliki tindakan buruk sebanyak 8 penjamah makanan $(19,5 \%)$ sedangkan penjamah makanan yang memiliki pengetahuan buruk dan tindakan

\section{PEMBAHASAN}

Pendidikan Penjamah Makanan

Dari 41 responden yang dilakukan wawancara terdapat 28 responden $(63,3 \%)$ berpendidikan tinggi, hal tersebut menunjukkan bahwa rata -rata pendidikan responden sudah cukup baik. Tingkat pendidikan dalam penelitian ini yaitu pendidikan formal yang telah ditamatkan oleh penjamah makanan dengan mendapatkan ijazah, sehingga 63,3\% penjamah makanan telah melaksanakan program pemerintah yaitu Wajib Belajar 9 tahun.

Responden yang sebagian besar menempuh pendidikan tertinggi SMA/ sederajat diperkirakan memiliki pengaruh terhadap tingkat pengetahuan yang diperoleh. Kurangnya pengetahuan mengenai akibat kebiasaan hidup tidak bersih serta pencemaran makanan yang terjadi karena memegang makanan secara langsung setelah memegang uang dikarenakan kebiasaan sehari-hari dari lingkungannya sehingga dianggap lumrah (Cahyaningsih, 2009)

Pendidikan berpengaruh terhadap perilaku penjamah makanan dalam peningkatan higiene sanitasi makanan. Pendidikan merupakan sarana untuk menyampaikan ilmu pengetahuan, semakin tinggi tingkat pendidikan penjamah makanan, maka semakin tinggi pengetahuannya dan semakin baik pula perilakunya dalam peningkatan higiene sanitasi makanan. baik sebanyak 2 penjamah makanan $(4,9 \%)$ dan penjamah makanan yang memiliki pengetahuan buruk dan tindakan buruk sebanyak 4 penjamah makanan $(9,8 \%)$.

\section{Pengetahuan Makanan}

Penjamah

Hasil penelitian menunjukkan bahwa penjamah makanan yang berpengetahuan baik sebanyak 37 responden $(90,2 \%)$. Pengetahuan yang benar tentang higiene sanitasi makanan bagi penjamah makanan merupakan syarat mutlak seorang bekerja dalam proses pengolahan, dan penyajian makanan untuk memperkecil faktor resiko terjadinya kontaminasi silang makanan (Mulyani, 2017). Pengetahuan merupakan hasil tahu dan ini terjadi setelah orang melakukan pengindraan terhadap suatu objek tertentu. Tahu diartikan sebagai mengingat suatu materi yang telah dipelajari sebelumnya, dan merupakan tingkat pengetahuan yang paling rendah (Notoatmodjo, 2010). Menurut peneliti bahwa pengetahuan yang baik tentang higiene sanitasi makanan bagi penjamah makanan belum tentu selaras dengan perilaku penjamah makanan. Selain pendidikan dan pengetahuan, masih banyak faktor lain yang berpengaruh terhadap perilaku penjamah makanan seperti kebiasaan dari penjamah makanan yang belum memperhatikan higiene dalam mengolah makanan, lingkungan yang tidak mendukung seperti tidak tersedianya alat pelindung diri (masker, celemek dan lain-lain) dan pelatihan yang telah diikuti oleh penjamah makanan tentang higiene sanitasi makanan. Penelitian ini tidak sejalan dengan penelitian Darwel (2017) bahwa pengetahuan penjamah makanan 
tentang personal higiene tergolong rendah yaitu hanya $27,23 \%$.

\section{Tindakan Penjamah Makanan}

Berdasarkan hasil penelitian menunjukkan bahwa dari 41 responden terdapat 28 responden $(68,3 \%)$ yang memiliki tindakan baik. Penelitian ini sejalan dengan penelitian Melialia (2017) menunjukkan bahwa $62,5 \%$ responden bertindak baik dan $37,5 \%$ bertindak cukup hal ini menunjukkan bahwa tindakan penjamah makanan mengenai higiene dan sanitasi makanan sudah cukup baik.

Notoatmodjo (2010) menyatakan bahwa sikap belum tentu terwujud dalam bentuk tindakan, sebab untuk mewujudkan tindakan perlu faktor lain, yaitu adanya fasilitas atau sarana dan prasarana sebagai mediator agar sikap dapat meningkat menjadi tindakan. Faktor penghambat yang mempengaruhi penjamah makanan bertindak kurang baik yaitu kebiasaan. Faktor kebiasaan merupakan hal tersulit untuk mengubah perilaku seseorang penjamah makanan karena sudah terbiasa dengan hal yang bertindak tidak baik. Hasil observasi masih ditemukan bahwa tindakan kebersihan diri penjamah makanan yang sebagian kecil tidak memenuhi aspek tindakan kebersihan diri, seperti tidak menjaga kebersihan (tangan, kuku dan rambut), tidak memakai celemek dan tutup kepala serta tidak mencuci tangan setiap kali hendak menangani makanan.

\section{Sikap Penjamah Makanan}

Hasil penelitian didapatkan bahwa dari 41 responden terdapat 39 responden $(95,1 \%)$ yang memiliki sikap baik dan 2 responden (4,9\%) yang meiliki sikap buruk. Sikap merupakan reaksi atau respon terhadap suatu stimulus atau objek. Manifestasi sikap tidak dapat dilihat langsung tetapi hanya dapat langsung ditafsirkan terlebih dahulu dari perilaku yang tertutup. Sikap belum merupakan suatu tindakan atau aktivitas, akan tetapi merupakan predisposisi tindakan suatu perilaku. Sikap masih merupakan kesiapan suatu reaksi terhadap objek di lingkungan tertentu (Notoatmodjo, 2010). Pembentukan sikap dipengaruhi oleh beberapa faktor yaitu pengalaman pribadi, orang yang dianggap penting, media massa, serta pendidikan dan agama (Azwar,2005).

Sikap merupakan hal penting dalam kehidupan sehari-hari, karena kalau sikap sudah terbentuk dalam diri seseorang maka sikap tersebut dapat ikut dalam menentukan tingkah laku terhadap sesuatu. Sikap agar menjadi suatu perubahan nyata perlu adanya kondisi tertentu yang kemungkinan antara lain adanya fasilitas dan dukungan (Notoatmojo, 2003). Hal ini menggambarkan bahwa sikap tidak selalu berhubungan dengan perilaku, karena sikap yang dikemukan belum tentu tercermin dalam perilaku yang kemungkinan dapat disebabkan karena adanya hambatan dan faktor ketiadaan sarana serta kesulitan responden untuk mempersepsikan jawaban dari kuesioner yang ada, sehingga responden cenderung untuk memberikan jawaban yang diharapkan.

Menurut peneliti upaya membiasakan /membudayakan kegiatan pencegahan, terhadap kontaminasi makanan memerlukan sikap konsisten serta butuh pengawasan dan kedisiplinan dari penjamah makanan sendiri. Sikap responden yang baik akan 
berhubungan dengan perilaku hygiene dalam mengolah makanan karena dianggap responden memahami betul pengetahuan tentang higiene dan sanitasi makanan, selain itu sikap juga dapat didasari oleh pengalaman yang didapat serta budaya yang biasa dilakukan, selain itu masih ada lagi yaitu dengan fasilitas yang tersedia. Seperti sikap responden yang didapat dari pertanyaan sikap kebanyakan responden sangat setuju dengan memakai pakaian kerja menggunakan celemek dan menutup kepala pada saat bekerja, mencuci tangan saat sebelum dan sesudah bekerja dengan menggunakan sabun, memegang makanan dengan menggunakan alat atau sarung tangan dan secara berkala rutin memeriksaan kesehatannya, tetapi karena keterbatasan fasilitas seperti tidak tersedianya masker atau peralatan yang kurang atau tidak tersedia sehingga mereka tidak menggunakan.

\section{Tindakan Penjamah Makanan BerdasarkanTingkat Pendidikan}

Hasil penelitian ini menunjukkan bahwa dari 41 penjamah makanan yang berpendidikan rendah memiliki tindakan baik sebanyak 3 penjamah $(7,3 \%)$ dan penjamah makanan yang berpendidikan tinggi memiliki tindakan baik sebanyak 25 penjamah $(61,0 \%)$, sedangkan penjamah makanan yang berpendidikan rendah memiliki tindakan buruk sebanyak 10 penjamah $(24,4 \%)$ dan penjamah makanan yang berpendidikan tinggi memiliki tindakan buruk sebanyak 3 penjamah (7,3\%).

Hasil penelitian ini sejalan dengan penelitian Rizka (2009), yang menujukkan bahwa ada 62 responden $\quad(71,3 \%) \quad$ yang pendidikannya tinggi ada 33 (37,9\%) responden dengan tindakan pengolahan yang baik, 29 (33,3\%) responden dengan tindakan pengolahan makanan yang buruk dan 25 responden $(28,7 \%)$ yang pendidikan rendah sebanyak 14 responden $(16,1 \%)$ dengan tindakan pengolahan makanan yang baik dan 11 responden $(12,6 \%)$ dengan tindakan pengolahan makanan yang buruk.

Pendidikan merupakan faktor yang sangat kuat untuk mengubah prilaku penjamah makanan, menurut Dimyanti dan Mudjiono (2009) bahwa pendidikan dapat meningkatkan kemampuan seseorang pada ranah kognitif, afektif dan psikomotorik. Ranah kognitif mencakup pengetahuan, pemahaman, dapat menerapkan, melakukan analisis, sintesis, dan mengevalusi. Ranah afektif meliputi melakukan penerimaan, partisipasi, menentukan sikap, mengorganisasi, membentuk pola hidup. Ranah psikomotorik berupa kemampuan untuk mempersepsi, bersiap diri, dan gerakan-gerakan. Penjamah makanan yang berpendidikan akan memiliki tindakan yang lebih baik tentang hygiene sanitasi makanan, dapat menentukan sikap dan mampu bersiap diri serta melakukan gerakan-gerakan untuk mengurangi risiko dari faktor-faktor pengelolaan makanan yang tidak higiene dan saniter.

\section{Tindakan Penjamah Makanan Berdasarkan Pengetahuan}

Berdasarkan hasil penelitian didapatkan bahwa dari 41 penjamah makanan, 27 penjamah makanan $(65,8 \%)$ yang memiliki pengetahuan baik dan memiliki tindakan baik dan yang memiliki pengetahuan baik 
dan memiliki tindakan buruk sebanyak 8 penjamah makanan $(19,5 \%)$ sedangkan penjamah makanan yang memiliki pengetahuan buruk dan tindakan baik sebanyak 2 penjamah makanan $(4,9 \%)$ dan penjamah makanan yang memiliki pengetahuan buruk dan tindakan buruk sebanyak 4 penjamah makanan (9,8\%). Hasil penelitian ini didapatkan bahwa makin baik pengetahuan penjamah makanaan maka akan semakin baik tindakan penjamah makanan.

Hal ini sejalan dengan penelitian Meliala (2017) yang menyatakan bahwa pengetahuan penjamah makanan tentang hygiene sanitasi makanan dengan tindakan hygiene sanitasi makanan, di dapatkan hasil bahwa semakin baik pengetahuan penjamah makanan tentang hygiene sanitasi makanan maka semakin baik juga tindakan penjamah makanan tersebut. Hasil penelitian sejalan dengan penelitian Roza Mulyani, 2014 bahwa responden dengan pengetahuan baik sebesar 59,5\%, mempunyai sikap baik $57,1 \%$ dan $52,4 \%$ berperilaku hygiene. Hasil analisa bivariat ada hubungan antara pengetahuan dengan perilaku hygiene ( $p$ value 0,032 ) $(0,032<0,05)$ dan tidak ada hubungan antara sikap dengan perilaku hygiene pengolah makanan ( $p$ value 0,562 ) ( $p$ value $>0,05)$. Hal ini sejalan dengan penelitian Amalia, dkk (2019) bahwa pengetahuan dan sikap semua staf pengolahan makanan termasuk dalam kategori yang baik.

Penelitian ini tidak sejalan dengan hasil penelitian Juherah, 2017 tentang perilaku penjamah makanan di Catering Anugerah dan Sekar Kota Makassar menunjukkan bahwa tingkat pengetahuan responden yang dikategorikan baik sebanyak 3 orang $(15 \%)$, sikap menujukkan bahwa tingkat pengetahuan yang dikategorikan baik sebanyak 4 orang $(20 \%)$, tindakan menunjukkan bahwa tingkat pengetahuan yang dikategorikan baik sebanyak 6 orang $(30 \%)$, sedangkan menurut Herdianti, dkk (2019) bahwa ada hubungan antara karakteristik dengan kebersihan sanitasi makanan dan ada hubungan antara perilaku penanganan makanan dengan kebersihan sanitasi makanan.

Pengetahuan didapat melalui pendidikan baik secara formal maupun non formal. Pengetahuan seseorang tentang higiene makanan dapat di peroleh dari penyuluhan oleh petugas sanitarian puskesmas atau media informasi (koran, radio, televisi). Dengan pengetahuan yang baik, maka seseorang akan berusaha mewujudkan apa yang diketahuinya. Sehingga pengelola rumah makan harus selalu meningkatkan pengetahuan penjamah makanan dengan cara mengikutsertakan penjamah makanan dalam pelatihan tentang higiene sanitasi pangan.

\section{SIMPULAN}

Kesimpulan dalam penelitian ini menunjukkan bahwa 28 responden $(63,3 \%)$ berpendidikan tinggi, 37 responden $\quad(90,2 \%) \quad$ yang berpengetahuan baik, 28 responden $(68,3 \%)$ yang memiliki tindakan baik, 39 responden (95,1\%) yang memiliki sikap baik, penjamah makanan yang berpendidikan tinggi memiliki tindakan baik sebanyak 25 penjamah $(61,0 \%)$, sedangkan penjamah makanan yang memiliki pengetahuan baik dan tindakan baik sebanyak 27 penjamah makanan $(65,8 \%)$.

\section{SARAN}

Disarankan kepada penanggung jawab rumah makan agar dapat lebih meningkatkan pengetahuan, sikap dan tindakan penjamah makanan dengan cara penjamah makanan 
diikutsertakan mengikuti pelatihan higiene sanitasi makanan dan kepada Dinas Kesehatan Kota Palembang agar dapat melakukan pengawasan secara berkala terhadap rumah makan dan mengadakan pelatihan bagi penjamah makanan yang ada di rumah makan padang yang ada di Kota Palembang dan hendaknya setiap rumah makan memiliki sertifikat Laik Higiene

\section{DAFTAR PUSTAKA}

Amalia S, Dkk (2019) Pengetahuan, Sikap Dan Personal Hygiene Tenaga Penjamah Makanan Di Ruang Pengolahan Makanan. Jurnal Gizi Prima. Vol.4, Edisi.2, September 2019, Pp. 81 86 Issn: 2656 - 2480 (Online) Issn: 2355 - 1364 (Print)

Azwar, A. (2005). Sikap Manusia: Teori dan Pengukurannya. Yogyakarta: Pustaka Pelajar.

Cahyaningsih CT, Kushadiwijaya $H$, Tholib A. (2009) Hubungan higiene sanitasi dan perilaku penjamah makanan dengan kualitas bakteriologis peralatan makan di warung makan. Berita Kedokteran Masyarakat.

Darwel, (2017) Pengetahuan, Sikap Dan Tindakan Penjamah Makanan Tradisional Di Pasar Pakandangan Kabupaten Padang Pariaman. Menara IImu Vol. Xi Jilid 2 No.76 Juli 2017jurusan Kesehatan Lingkungan Poltekkes Kemenkes Padang. Email : Wel_Piero@Yahoo.Com

Herdianti, dkk (2019) Perilaku dan Karakteristik Penjamah Makanan Terhadap Higiene Sanitasi Makanan Pada Rumah
Makan.

https://www.ejournal.Ippmuni dayan.ac.id/inde

x.php/kesmas. e-ISSN: 25496654. P-ISSN: 2338-610x. Kampurui Jurnal Kesehatan masyarakat

Juherah , Dkk (2017) Perilaku Penjamah Makanan Di Catering Anugerah Dan Sekar Kota Makassar Jurnal Sulolipu : Media Komunikasi Sivitas Akademika Dan Masyarakat. Vol. 17 No 12017

Kemenkes RI. Peraturan Menteri Kesehatan Republik Indonesia Nomor 1098/Menkes/Per/VII /2003 tentang persyaratan higiene rumah makan dan restoran

Mulyani, R. (2017). Pengetahuan, Sikap Dan Perilaku Higiene Pengolah Makanan. Jurnal Keperawatan, 10(1): 6-12.

Notoatmodjo,S., dkk. (2003). Pengantar Ilmu Perilaku. FKM, Ui Jakarta 2003

Notoatmodjo S. 2010. Ilmu Perilaku Kesehatan. Jakarta: PT Rineka Cipta.

Puskesmas Basuki Rahmat, 2019. Profil Puskesmas Basuki Rahmat.

Rizka Putra, (2009). Hubungan Pengetahuan dan Sikap Pramusaji Terhadap Hygeine Sanitasi Makanan dengan Tindakan Penyajian Makanan di Rumah Makan Padang Kota Palembang Tahun 2009.

Roza Mulyani (2014). Pengetahuan, Sikap Dan Perilaku Higiene Pengolah Makanan. Jurnal Keperawatan, Volume $X$, No. 1, April 2014 Issn 1907 - 0357 